Stephan G. Grimmelikhuijsen

Albert J. Meijer

Utrecht University, The Netherlands

\title{
Does Twitter Increase Perceived Police Legitimacy?
}

Stephan G. Grimmelikhuijsen is assistant professor at Utrecht University in The Netherlands. He has published on topics such as public sector transparency, citizen trust and perceived legitimacy, red tape, and social media.

E-mail: s.g.grimmelikhuijsen@uu.nl

Albert J. Meijer is full professor of public management at Utrecht University in The Netherlands. He has published research on issues such as public innovation, coproduction in the public sector, social media, and government transparency. He is chair of the Permanent Study Group on E-Government of the European Group for Public Administration and serves on the editorial board of the journal Information Polity.

E-mail: a.j.meijer@uu.n
Public Administration Review Vol. 75, Iss. 4, pp. 598-607. (C) 2015 by The American Society for Public Administration. DOI: $10.1111 /$ puar. 12378

Abstract: Social media use has become increasingly popular among police forces. The literature suggests that social media use can increase perceived police legitimacy by enabling transparency and participation. Employing data from a large and representative survey of Dutch citizens $(N=4,492)$, this article tests whether and how social media use affects perceived legitimacy for a major social media platform, Twitter. A negligible number of citizens engage online with the police, and thus the findings reveal no positive relationship between participation and perceived legitimacy. The article shows that by enhancing transparency, Twitter does increase perceived police legitimacy, albeit to a limited extent. Subsequent analysis of the mechanism shows both an affective and a cognitive path from social media use to legitimacy. Overall, the findings suggest that establishing a direct channel with citizens and using it to communicate successes does help the police strengthen their legitimacy, but only slightly and for a small group of interested citizens.

\section{Practitioner Points}

- Twitter helps strengthen legitimacy, albeit slightly.

- The reach of communication using Twitter is limited. Twitter is useful for targeted messages for a specific public, but less so to inform a broad audience.

- Twitter is hardly used to interact with the police. Specific attention to the design of a social media strategy is needed to better involve citizens.

$\mathrm{O}$ pen government is supposed to strengthen government legitimacy by means of two main pillars: transparency and participation (Bertot, Jaeger, and Grimes 2010; Meijer, Curtin, and Hillebrandt 2012). The increasing use of social media in the public domain has the potential to strengthen these pillars simultaneously. Recent studies have emphasized that social media may contribute to open government by lowering the transaction costs of information disclosure to and interactions with citizens (Kim, Park, and Rho 2015; McDermott 2010; Mergel 2012a; Yi, Oh, and Kim 2013, 310). Following up on these expectations, police forces around the world have been developing new social media strategies to inform and interact with citizens (Crump 2011; Meijer et al. 2013; Oliveira and Welch 2013; Perin 2009).

One of the most promising social media platforms for creating information access and easy interaction with public officials is Twitter. Citizens can now use Twitter to inform the police about suspects, missing persons, or other issues in their neighborhood (Bertot, Jaeger, and Grimes 2010; Bonsón et al. 2012; Kim, Park, and Rho 2015). Several examples illustrate the strategic importance of this social media platform for transparency and participation. The Toronto Police
Department in Canada embeds the use of social media in its strategies for building better relationships with different citizen groups (Meijer and Thaens 2013). Crump (2011) describes how the London police in the United Kingdom used Twitter, Facebook, YouTube, Flickr, and "hyperlocal" message boards to provide highly localized information about what occurred during the London riots in 2011. In a study conducted in the United States, Heverin and Zach (2011) found that police departments use Twitter for not only for distributing information about crime and incidents but also for disseminating information about events, traffic, and crime prevention. The Dutch police have also become very active on Twitter: in 2012, more than 1,000 Twitter accounts sent over 500,000 tweets. The most popular Twitter accountthat of The Hague Police Department-had more than 20,000 followers. Although many believe in the contribution of Twitter to improving relations between police and citizens, Twitter can also have an adverse effect. For instance, in 2014, the New York City Police Department asked people to tweet pictures of themselves with police officers using the hashtag \#MyNYPD. Many people responded, but in an unanticipated way: most responses were negative and gave examples of citizens being mistreated by the police. 
Social media use by public organizations has attracted the attention of scholars. Mossberger, Wu, and Crawford (2013), for example, have studied the increased adoption of Facebook and Twitter in local governments, and various scholars have shown how social media can be used strategically (Campbell, Lambright, and Wells 2014; Mergel 2013; Mergel and Bretschneider 2013). However, the literature is still scant as to the effects of social media on citizens' attitudes and, specifically, on perceived legitimacy. This is particularly relevant to policing and perceived legitimacy because solving crimes and ensuring public safety greatly depend on cooperation from the community (Tyler 2004). Therefore, this article analyzes how and to what extent social media contributes to perceived police legitimacy.

Some researchers believe that social media enhances legitimacy because of its presumed capacity to improve transparency and strengthen citizen participation (Bertot, Jaeger, and Grimes 2010; Kim, Park, and Rho 2015; Mossberger, Wu, and Crawford 2013; Oliveira and Welch 2013; Yi, Oh, and Kim 2013). A less understood reason is that social media use conveys the message that the police are a modern organization in touch with society (cf. Bekkers and Homburg 2007). This image of modernity might have a positive effect on the perceived legitimacy of the police. However, Twitter and other social media can actually decrease perceptions of police legitimacy. As the Twitter backfire in New York City shows, Twitter can help citizens disseminate negative images and/or stereotypes of police, which may undermine their support for the police. Experimental evidence into government transparency seems to confirm this negative effect (de Fine Licht 2011; Grimmelikhuijsen et al. 2013).

In sum, police and other public service providers are increasingly present on Twitter and other social media, but the effects on perceived legitimacy are debated and understudied. Therefore, we examine the following central question: To what extent, how, and why does Twitter use by citizens contribute to perceived police legitimacy?

This article provides a key contribution to our understanding of the relationship between social media use and perceived police legitimacy by reporting findings from a survey of 4,492 citizens in the Netherlands including social media users and nonusers. By using a large sample that is representative in terms of age, sex, and education, this survey can establish relationships and patterns between social media use and perceived legitimacy.

The analysis is instrumental in understanding open government by testing the theoretical mechanisms through which social media use contributes to perceived legitimacy. In addition, the analysis shows the extent and magnitude of the relationship between social media and legitimacy using structural equation modeling.

\section{Social Media for Open Government}

Social media communications can be seen as one of the technological drivers of open government programs (Mergel 2013). Meijer, Curtin, and Hillebrandt present the following definition of open government: "Openness of government is the extent to which

citizens can monitor and influence government processes through access to government information and access to decision-making arenas" $(2012,13)$.

A variety of platforms, such as Twitter, Facebook, Google+, and YouTube, allow public agencies to foster engagement with citizens and representative organizations (Criado, Sandoval-Almazan, and Gil-Garcia 2013). Bertot, Jaeger, and Hansen $(2012,30)$ indicate that social media refers to a set of online tools that are designed for social interaction. The more precise term is "social network sites." Boyd and Ellison provide the following comprehensive definition: "We define social network sites as web-based services that allow individuals to (1) construct a public or semipublic profile within a bounded system, (2) articulate a list of other users with whom they share a connection, and (3) view and traverse their list of connections and those made by others within the system" $(2007,211)$.

The microblogging platform Twitter is a specific type of a social networking site in the sense that it enables the user to send only brief messages (140 characters). Twitter users can share messages with other groups by forwarding them or commenting on them. In addition, it is an asymmetric medium: users can follow an account without being followed. These features make Twitter particularly useful for disseminating short messages to specific user groups.

Over the past several years, use of social media by governments to communicate with citizens has exploded (see, e.g., Mossberger, Wu, and Crawford 2013). Mergel (2012a) shows that in 2012, the 698 departments, agencies, and initiatives of the U.S. federal government had already created 2,956 Facebook pages, 1,016 Twitter accounts, 695 YouTube channels, and 498 Flickr pages. This number is probably a low estimate, as it only acknowledges formal and central use.

The popularity of social media might be explained by its limited cost, and high expected benefits may explain the current surge in social media use. A key advantage of social media is that no expensive technology and no complex skills are needed to use them (Mergel 2012b). In contrast to previously introduced e-government systems, such as websites and forums, individual users can immediately start using social media. Organizations do not need to invest in expensive new technology, and the promise of social media is high (Bertot, Jaeger, and Grimes 2010; Criado, Sandoval-Almazan, and Gil-Garcia 2013).

Governments that only use social media to deliver messages to citizens and never ask for feedback or react to comments or posts from citizens limit their ability to communicate.
Many authors have explored social media from the perspective of government organizations (e.g., Bertot, Jaeger, and Grimes 2010; Campbell, Lambright, and Wells 2014; Crump 2011; Mergel 2013; Mossberger, Wu, and Crawford 2013). These analyses treat social media use as a strategic choice by government organizations, but it is important to note that the pattern of social media use results from the actions of both governments

and citizens. Governments that only use social media to deliver messages to citizens and never ask for feedback or react to comments or posts from citizens limit their ability to communicate. However, communication may also take the form of informing, such that 
citizens only read government messages and never react or interact with these government organizations. Interactive patterns result from the actions of both governments and citizens.

This discussion highlights the need to analyze social media in the context of open government in terms of interactive and informative use of social media from the perspective of both government organizations and citizens. Currently, few studies have investigated how citizens use social media to communicate with governments and how these contacts influence their perceptions.

\section{Impacts of Social Media Use on Perceived Legitimacy}

A key aim of social media policies is to improve perceived legitimacy. In his seminal work on legitimacy, Weber (1968) argued that people's adherence to the instructions of authorities is caused not only by the power that an authority wields over them. At the core of legitimacy is a voluntary compliance with authority. Voluntary compliance means that people do not "just" comply with the law out of fear of punishment but choose to do so voluntarily. Legitimacy stems from an internalized feeling to willingly obey authority or rules, without any actual coercion from authorities (Lipset 1959; Tyler 1997), which is a crucial notion for the effectiveness of law enforcement agencies such as the police. In this article, we adhere to the much-cited definition of legitimacy by Suchman: "Legitimacy is a generalized perception or assumption that the actions of an entity are desirable, proper, or appropriate within some socially constructed system of norms, values, beliefs, and definitions" $(1995,574)$.

This definition first shows that legitimacy is "generalized": it transcends a single incident. Legitimacy is not built overnight but takes time to develop and extend. Second, Suchman refers to "perception or assumption" in his definition. In this article, we focus on subjective legitimacy because of the importance of citizens' perceptions in social media use. Third, legitimacy is socially constructed. This part of the definition reflects the consonance between the acts of the organization and the shared beliefs of a community. The quest for legitimacy is of specific relevance to the police because effective policing without legitimacy is hardly feasible: police work relies on legitimacy for voluntary citizen support (Hinds and Murphy 2007; Tyler 1997).

Legitimacy theorists stress that organizations continuously interact with relevant stakeholders in their environment to sustain their legitimacy (Elsbach 1994; Suchman 1995; Suddaby and Greenwood 2005). Organizational legitimation through interaction with the environment has taken a new turn with the emergence of social media, which may contribute to two important sources of police legitimacy: perceived effectiveness and perceived procedural fairness (Hawdon, Ryan, and Griffin 2003; Tyler 2004, 2006). Perceived effectiveness is instrumental and based on police performance and outcomes, whereas perceived procedural fairness highlights the rightness of processes and treatment of citizens (Scharpf 1999; Suchman 1995; Tyler 1997).

Perceived effectiveness is an outcome-based source of legitimacy that results from positive citizen evaluations of the effectiveness of public organizations. Suchman notes that in order to achieve legitimacy, an organization must meet the substantive needs of its audience. Ultimately, a strategy for seeking organizational legitimacy is "actually to produce concrete, meritorious outcomes" (Suchman 1995, 587-88). We call this source of legitimacy perceived effectiveness, and we expect this to be related to social media use because social media strengthens transparency and participation. The basic argument for the relationship between transparency and perceived effectiveness is that citizens perceive government as being effective if it informs them about policies that yield good results (Grimmelikhuijsen and Meijer 2014). As for the relationship between participation and perceived effectiveness, the reasoning is that citizens may enhance an organization's effectiveness by providing input. For example, citizens can use Twitter to help police forces solve crimes by providing additional information. The expectation is that this type of engagement results in a more positive evaluation of the organization's performance (see Fledderus, Brandsen, and Honingh 2014).

In contrast, scholars have recently found that increased transparency can also have a negative effect on perceived effectiveness (see de Fine Licht 2011; Grimmelikhuijsen et al. 2013). For instance, when police tweet negative messages about their performance or make appeals for help with unsolved cases, the public may view the police as being less effective. That said, our focus is on the messages tweeted by the police, which are more focused on their achievements than on their failures. In that sense, only a one-sided form of transparency is being created. Considering the foregoing, we formulate the following hypotheses:

Hypothesis 1: Higher levels of perceived effectiveness are associated with higher levels of perceived legitimacy.

Hypothesis 2: Informative use of Twitter by citizens (transparency) is associated with higher levels of perceived effectiveness.

Hypothesis 3: Interactive use of Twitter by citizens (participation) is associated with higher levels of perceived effectiveness.

Another source of legitimacy is perceived procedural fairness. This dimension is based on citizens' perceptions of fair treatment by the police. Perceived procedural fairness has been found to be an important predictor of legitimacy (Sunshine and Tyler 2003; Tyler 2003, 2004). Tyler and Degoey (1995) found that citizen support increases when people feel that procedures are fair and that positive, relational bonds with authorities determine procedural fairness. Perceived procedural fairness entails various dimensions of government-citizen interaction. For example, being treated with respect and being given voice are dimensions of citizen-government interactions (Van den Bos, Vermunt, and Wilke 1997). Overall, we expect perceptions of procedural fairness to result in more perceived legitimacy.

Twitter's ability to increase both transparency and participation may enhance this procedural source of legitimacy. The argument for a positive relationship between the transparency generated by social media and perceived procedural fairness is that we expect 
citizens to view government as fair when they are informed about correctly followed procedures and when they are treated fairly (Grimmelikhuijsen and Meijer 2014). The participative function of Twitter may also increase perceived procedural fairness. The expectation is that citizens perceive government as fair when interaction is possible and government deals with their input in a fair manner. This argument underlies many initiatives of (online) citizen participation (see, e.g., Bingham, Nabatchi, and O'Leary 2005). Based on these arguments, we propose the following hypotheses:

Hypothesis 4: Higher levels of perceived procedural fairness are associated with higher levels of perceived legitimacy.

Hypothesis 5: Informative use of Twitter by citizens (transparency) is associated with higher levels of perceived procedural fairness.

Hypothesis 6: Interactive use of Twitter by citizens (participation) is associated with higher levels of perceived procedural fairness.

Apart from these cognitive relations between social media use and perceived legitimacy-changes in perceptions of effectiveness and fairness affecting perceived legitimacy-we suggest an affective relationship between social media use and perceived legitimacy. This argument builds on the literature on trust, which identifies two routes to trust: knowledge-based or cognitive trust and affective trust (see Lewis and Weigert 1985; McAllister 1995). For instance, the fact that the police have adopted social media-regardless of the exact content-as a modern communication channel may show citizens that the police are in touch with current developments in society to inform and interact with them. This type of "modern behavior" is expected to directly enhance police legitimacy (Bekkers and Homburg 2007). Evaluations of police may not necessarily be dependent on actual use of Twitter, but merely being aware of the police employing social media might give citizens the feeling that the police are legitimate. This affective relation is particularly heightened when citizens actually follow the police on Twitter. This argument forms the basis for our final hypothesis:

Hypothesis 7: Use of Twitter by citizens is directly associated with higher levels of perceived legitimacy.

We present a model to describe the relationships between variables in figure 1.

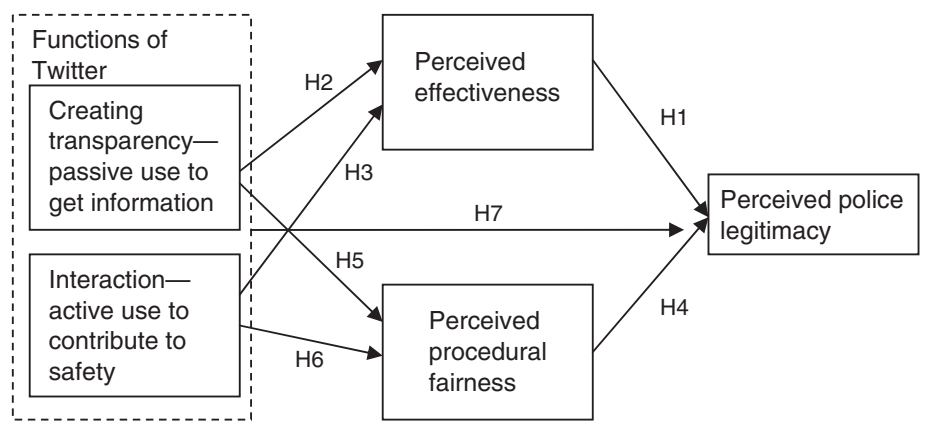

Figure 1 Model of Relations between Police Communications and Legitimacy
Figure 1 shows that transparency is achieved mainly when citizens use Twitter passively to receive police information, whereas participation is attained by interaction and exchange of information. Furthermore, we should note that although we use theoretical assumptions about the direction of each separate causal effect, this study is cross-sectional and thus cannot provide any conclusive evidence about cause and effect in this model. We will go over this issue in greater detail in the Discussion section.

\section{Institutional Context: Social Media in the Dutch Police Forces}

Until 2013, the Dutch police were divided into relatively autonomous regional police forces. In 2013, these regional forces were merged into the "National Police" with the idea that this would increase the effectiveness and efficiency of the police force. One of the strategic priorities of this new organization is to enhance its legitimacy, which underlines the relevance of this study (Nationale Politie 2012).

The use of social media by the Dutch police force forms an interesting case, ${ }^{1}$ as the police have gained an impactful and "exciting" image through crime reality television shows (Fishman and Cavender 1998). The expectation is that citizens will also be highly interested in police communications. In addition, police forces in the Netherlands are already using social media platforms such as Twitter extensively (Meijer et al. 2013). Although comparative studies are scant, this indicates that the Netherlands may be ahead of most countries with regard to strategic use of social media and Twitter by the police. This is perhaps related to the widespread use of social media in the Netherlands. According to Eurostat, an average of 40 percent of European Union citizens between 16 and 75 years old were using social media in 2011. In the Netherlands, this percentage was 60 percent, making the Netherlands the country with the most social media users in the European Union.

The Dutch police are mostly using Twitter but also, to some extent, YouTube, blogs, and Facebook to communicate with citizens. In 2012, there were more than 1,000 Twitter accounts in total, which sent more than 500,000 tweets. The police use Twitter to strengthen contacts with citizens, boost feelings of safety, improve their image and knowledge about its forces, and obtain information from citizens (Meijer et al. 2013). The content of social media use is quite diverse but includes information for citizens, requests for cooperation, and communication of "successes." For instance, the Dutch police tweet messages about criminals who have been apprehended, send informative messages about traffic situations, and issue warnings about specific crime schemes. They also ask citizens information about (petty) crime and inform them about neighborhood safety, urging citizens to stay alert for certain types of crime such as burglaries.

\section{Research Methods and Design Sample and Data Collection}

We carried out a cross-sectional survey for this study. Although we are aware this is not suitable for inferring causal relations empirically, this design enabled us to gather data on many variables on a large number of subjects. Data were collected using the LISS (Longitudinal Internet Studies for the Social Science) panel. The LISS panel data, managed by CentERdata at Tilburg University in the Netherlands, is a representative sample of Dutch individuals 
who participate in monthly Internet surveys. The panel is based on a true probability sample of households drawn from the population register. Households that could not otherwise participate are provided with a computer and Internet connection. (More information about the LISS panel can be found at http://www.lissdata.nl.) In total, 4,492 respondents were included in the sample from 6,096 targeted respondents. The response rate was 73.8 percent, of which 73.7 percent $(4,492)$ completed the questionnaire. The incomplete questionnaires were omitted from the data set and not used for further analysis.

Our sample is, by and large, representative of the Dutch population regarding three key background variables: percentage with a vocational education or higher (30.4 percent in the sample, 27.6 percent in the population), percentage female ( 53.6 percent in the sample, 50.8 percent in the population), and age (50.0 in the sample, 47.4 in the population). We took these background variables into account as control variables for any confounding effects on the outcome variables. In addition, we included the following control variables to allow for potential confounding effects such as perceived safety, measured on a scale from 1 ("very unsafe") to 5 ("very safe"), and recent victimhood of crime, measured as yes/no, regardless of the crime. A more detailed overview of our control variables can be found in the appendix.

\section{Measures}

A full inventory of all items and Cronbach's alphas is listed in the appendix. These items are based on a literature review and were tested in a previous (small) online pilot study $(N=115) .{ }^{2}$ To measure the transparency route toward legitimacy, we asked whether respondents used Twitter to-passively_-follow a police account. For the participation route, we asked respondents whether they had ever been in touch with the police because of something they had seen on Twitter. We included a question about whether participants had ever watched an informative television show to be informed about and interact with the police (both measured on a binary yes/ no scale). In doing so, we have the potential to compare our findings pertaining to Twitter with a more traditional media outlet, which helps us interpret the results.

To measure perceived effectiveness, perceived procedural fairness, and perceived legitimacy, we translated and adapted from scales used by Tyler (1997) and Hinds and Murphy (2007). Tyler has been very influential in research on perceived legitimacy and procedural fairness, whereas Hinds and Murphy have applied Tyler's work to law enforcement agencies specifically. We measured perceived effectiveness by three items (alpha $=0.823$, range $1-5$ ), one of which is the item EFFECT1: "the police successfully fight crime." Perceived procedural fairness included items related to the perceived treatment of citizens by the police. For instance, PROCESS1 stated, "In the execution of their tasks, the police respect citizens' rights" (three items, alpha = .848 , range $1-5)$. To measure our main dependent variable, perceived legitimacy (four items, alpha $=.829$ ), items included references to trust and citizen support for the police; for instance, LEGIT1 stated, "I have much respect for the work of the police."

\section{Data Analysis}

The data were analyzed using structural equation modeling with R 3.0.2 (R Development Core Team 2008). This method consists of two steps (Anderson and Gerbing 1988): first the measurement model is estimated, and then the proposed structural model is tested. The measurement model is estimated in this section, and the structural model (i.e., the actual theoretical model test) is presented in the Findings section.

We conducted a confirmatory factor analysis (CFA) to assess the structure of the variables. This checks whether the theoretical distinction in three dimensions (latent variables) is supported by the data. CFA examines the fit of the data with our theoretical model and shows whether and where the model needs modifications in order to improve the fit. Next, we assessed reliability by examining the coefficients of Cronbach's alphas.

To determine the model fit, we estimated the comparative fit index (CFI), Tucker-Lewis index (TLI), and the root mean square error of approximation (RMSEA). CFI and TLI indexes of .90 or higher and a RMSEA of .08 or lower provide evidence of an acceptable fit (Bentler 1990). After applying two modifications to the model (allowing error correlations between observed variables within the perceived effectiveness and perceived legitimacy construct: EFFECT1 and EFFECT3, LEGIT1 and LEGIT2), the overall fit of the variable structure was acceptable $(\mathrm{CFI}=.977, \mathrm{TLI}=.965$, RMSEA $=.071)$. This is a good fit and means that the data support the theoretical concepts.

The remainder of our data analysis consists of the following two steps. First, we used descriptive statistics to estimate whether a form of social media use (passive or interactive) occurred in the sample and, if so, the extent to which the type of use occurred. Next, we used structural equation modeling to assert the significance and magnitude of the relationship in our model.

\section{Findings}

On the basis of our empirical data, we determined what percentage of the total population uses Twitter to either obtain information from or interact with the Dutch police. In addition, we tested whether a significant relationship is present for the various relations in the model. Also, we examined the magnitude of the relationships.

\section{Analysis of Social Media Use by Dutch Citizens}

The first analysis assessed what percentage of the population actually uses Twitter to obtain information from the police or interact with them. Table 1 uses descriptive statistics for this analysis.

Table 1 Descriptive Statistics for All Variables $(N=4,492)$

\begin{tabular}{|c|c|c|c|c|}
\hline & Range & Mean & SD & $N$ (if relevant) \\
\hline \multicolumn{5}{|l|}{ Dependent variables } \\
\hline Perceived legitimacy & $1-5$ & 3.59 & .70 & - \\
\hline Perceived effectiveness & $1-5$ & 3.30 & .77 & - \\
\hline $\begin{array}{l}\text { Perceived procedural fairness } \\
\text { Use of social media (police) }\end{array}$ & $1-5$ & 3.34 & .77 & - \\
\hline Passive use of Twitter & $0-1$ & .03 & .18 & 155 \\
\hline $\begin{array}{l}\text { Interactive use of Twitter } \\
\text { Contro/ variables }\end{array}$ & $0-1$ & .00 & .026 & 3 \\
\hline Passive use of old media (TV) & $0-1$ & .36 & .48 & 1,608 \\
\hline Active use of old media (TV) & $0-1$ & .01 & .087 & 34 \\
\hline Gender ( 2 = female $)$ & $1-2$ & 1.54 & .49 & - \\
\hline Age & $16-92$ & 49.99 & 17.44 & - \\
\hline Education (1 = high) & $0-1$ & .30 & .46 & - \\
\hline Perceived safety ( $5=$ very safe) & $1-5$ & 3.89 & 1.04 & - \\
\hline Victim preceding year & $0-1$ & .06 & .25 & 289 \\
\hline
\end{tabular}


Table 1 shows the descriptive results for all variables that will be entered into the equation. It indicates that people generally have a moderate level of support for the police. Based on a five-point scale, perceived legitimacy is given a mean score of 3.59 , which is slightly above the neutral score of 3.0. The same is true with regard to perceived effectiveness (3.30) and perceived procedural fairness (3.34) of the police. Looking at the control variables, we observe that slightly more women than men are included in the sample, and the average age is around 50 years old. In general, respondents indicated that they feel fairly safe in their neighborhood and/or city.

Noticeably, the independent variables show that only a limited number of respondents had ever used Twitter to contact the police: interactive use is thus minimal. Because of this very low $N$, we could not include these variables in the regression model because one or two respondents could easily bias the results. This means that the relation between the interactive use of social media and perceived effectiveness and perceived procedural fairness is not asserted. We can observe, however, that interactive use hardly occurs and therefore cannot have a substantial influence on police legitimacy.

Among the respondents, 155 indicated they follow police accounts on Twitter, which represents 3.4 percent of the total sample. This is a low percentage compared with 35.8 percent of respondents who "use" informative police television programs. In comparison, 15.2 percent said they use Twitter, but very few have used Twitter to interact with police forces. In sum, social media use may be on the rise, but the overall use for public purposes is still rather limited.

\section{Analysis of Significance and Magnitude of Relationships}

We ran three models to assess which one fit best with our data. The first model estimates only the direct effect of passive Twitter use on perceived legitimacy. The second model asserts a full mediation model, with perceived procedural fairness and effectiveness as mediating variables. Model 3 shows the results for a partial mediation effect - that is, both a direct effect and a mediated effect of Twitter on perceived legitimacy. Table 2 shows the results of the structural equation analysis on the three models.
Table 2 shows three model tests; based on our hypotheses, we expect the third model (the partial mediation model) to best fit our data. We will compare each model and assess whether model 3 has the best fit indexes. Model 1 represents a direct effect of Twitter use only. However, the fit indexes at the bottom of table 2 indicate that model 1 has a poor fit with the data. Most notably, the goodnessof-fit (GFI) index is below the commonly accepted threshold of .90 , and the root mean square error of approximation (RMSEA) of .105 is above the .05 or even .08 threshold. The two other models, the fully mediated and partially mediated model, provide far better fit indexes. First, in both cases, the RMSEA statistic indicates a good model fit (RMSEA $=.052, .053$ ). Further, the other measures of fit, which compare the specified model to a "perfectly fitting" model, are well above the .90 threshold (Bentler 1990), reflecting a good model fit (goodness-of-fit index $=.956, .957$ ). These fit indexes mean that our empirical data support theoretical models 2 and 3.

The next question is, which model is best supported by the data? To assess this, we use the Akaike information criterion (AIC), an estimate that is often used to compare models with each other. A lower AIC indicates a better fit with the data, and this shows that the partial mediation model has a slightly better fit. Because the differences are so small, a more decisive test is the $\chi^{2}$ (chi-square) difference test. This test works as follows: Models with the lowest $\chi^{2}$ are preferred because this indicates a better fit with the data. In case there is no significantly lower $\chi^{2}$, the most parsimonious model (i.e., least complex, in our case the fully mediated model) is preferred (Yuan and Bentler 2004). To test this, we computed $\chi^{2}$ and degrees of freedom for each model and then calculated whether the differences were significant. The test showed that the most parsimonious model (full mediation model) had significantly worse fit than the less parsimonious model (i.e., the partial mediation model, $\Delta \chi^{2}=$ $10.144, \Delta d f=1, p<.001)$. This means that the least parsimonious model - the partial mediation model —is the preferred model with the current data.

When we move to the standardized coefficients of the partial mediation model — that is, the specific relationships in the model — the following can be observed: First, perceived procedural fairness seems

Table 2 Effect of Twitter Use on Perceived Legitimacy

\begin{tabular}{|c|c|c|c|c|c|c|}
\hline & \multicolumn{2}{|c|}{ Model 1: Direct Effect Only } & \multicolumn{2}{|c|}{ Model 2: Full Mediation } & \multicolumn{2}{|c|}{ Model 3: Partial Mediation } \\
\hline & Indirect Effect & Direct Effect & Indirect Effect & Direct Effect & Indirect Effect & Direct Effect \\
\hline Twitter use & & $.050 * * *$ & $\begin{array}{l}\text { PF: } .018 \\
\text { PE: } .038^{* * *}\end{array}$ & & $\begin{array}{l}\text { PF: } .013 \\
\text { PE: } .035^{*}\end{array}$ & $.029 * *$ \\
\hline \multicolumn{7}{|l|}{ Mediators } \\
\hline Perceived procedural fairness & & & & $.546 * * *$ & & $.545 * * *$ \\
\hline \multicolumn{7}{|l|}{ Controls } \\
\hline Watched informative police TV shows ( 1 = yes) & & .006 & & .007 & & .006 \\
\hline Sex $(1=$ male, $2=$ female $)$ & & $.057 * * *$ & & $.030 * * *$ & & $.031 * * *$ \\
\hline Age & & $.105 * * *$ & & $.058 * * *$ & & $.061 * * *$ \\
\hline Education ( 1 = vocational education and higher) & & $.076 * * *$ & & $.055 * * *$ & & $.055 * * *$ \\
\hline Perceived safety & & $.174 * * *$ & & $.050 * * *$ & & $.041 * * *$ \\
\hline \multirow[t]{6}{*}{ Victim (1 = yes) } & & -.001 & & .007 & & .006 \\
\hline & \multirow{2}{*}{\multicolumn{2}{|c|}{ Adjusted $R^{2}=.0575$}} & \multicolumn{2}{|c|}{ Adjusted $R^{2}=.8470$} & \multicolumn{2}{|c|}{ Adjusted $R^{2}=.8477$} \\
\hline & & & \multicolumn{2}{|c|}{$\chi^{2} / d f=13.43$} & \multicolumn{2}{|c|}{$\chi^{2} / d f=13.46$} \\
\hline & \multicolumn{2}{|c|}{$\begin{array}{c}\chi^{2} / d f=50.60 \\
\mathrm{GFI} .899\end{array}$} & \multicolumn{2}{|c|}{ GFI .956} & \multicolumn{2}{|c|}{ GFI .957} \\
\hline & \multicolumn{2}{|c|}{ RMSEA .105 } & \multirow{2}{*}{\multicolumn{2}{|c|}{$\begin{array}{l}\text { RMSEA .052 } \\
\text { AIC } 1805.39\end{array}$}} & \multicolumn{2}{|c|}{ RMSEA .053 } \\
\hline & \multicolumn{2}{|c|}{ AIC 6708.70} & & & $\mathrm{AlC}$ & 26 \\
\hline
\end{tabular}

Notes: Structural equation model. Standardized beta coefficients are shown. PF $=$ Perceived procedural fairness $/$ PE $=$ Perceived effectiveness

${ }^{*} p<.05 ;{ }^{*} p<.01 ; * * * p<.001$. 
to have a limited effect. Following Twitter does have a positive relationship with procedural fairness $(\beta=.013)$, but it is insignificant. Second, table 2 shows that the indirect effect of social media use through perceived effectiveness is significant and positive $(\beta=.035$, $p<.05)$. The third effect in the partial mediation model is the direct effect of Twitter on perceived legitimacy, .029 $(p<.01)$. This indicates a positive relationship between Twitter use and perceived legitimacy. Furthermore, the relationships between the two moderators and perceived legitimacy are strong, .545 for perceived procedural fairness and .418 for perceived effectiveness. The high beta coefficients are a warning sign of multicollinearity. However, the variance inflation statistics were all below 2.0, and tolerance statistics were above 0.5 . A tolerance of less than 0.20 or 0.10 and/or a VIF of 5 or 10 and higher indicates a multicollinearity problem, which is not the case here.

\section{Discussion}

The central question of this study was, to what extent, how, and why does Twitter use by citizens contribute to perceived police legitimacy? By answering the first part of the question ("to what extent"), this study provides an important contribution about the magnitude of the effect of social media use on perceived legitimacy. Our analysis showed that only a small percentage of the population use Twitter (3.5 percent) to receive information. Furthermore, we observed that the participative use of social media for interaction (0.1 percent) is even too limited to carry out a meaningful statistical analysis. Interactive use does not strengthen police legitimacy in a significant way. Comparing this to the low interactive use of informative police television shows ( 0.8 percent), these findings can be placed into perspective: the proportion of interactive media users is apparently rather low, regardless of the type medium (social or "old" media). This is remarkable, given the many commentators who have highlighted the revolutionary and interactive possibilities of social media for the public domain.

This does not mean that social media use has no effect at all. Our analysis indicates that-in line with the current body of research in e-government and transparency (de Fine Licht et al. 2013; Grimmelikhuijsen and Meijer 2014; Morgeson, VanAmburg, and Mithas 2010; Tolbert and Mossberger 2006;

Welch, Hinnant, and Moon 2005) — the relationship between Twitter use and perceived legitimacy is positive. This said, our findings debunk the idea that Twitter heralds the dawn of an age of frequent interactions between citizens and government organizations. Even for the police-which greatly rely on contacts with citizens - participation through Twitter is limited.

The research clearly indicates that transparency, not participation, is the dominant effect of Twitter. Although participation may be very important for enhancing the effectiveness of police, as a few good tips may have a huge effect, our research provides no support for the value of online participation in strengthening perceived legitimacy in the near future. However, in the long run, Twitter, as a means of making government more open, could prevent the abuse of power through "monitorial citizenship" (Keane 2009; Schudson 1998). Monitorial citizens tend to be well informed and watchful, in the sense that they engage in surveillance without really being proactive responders. "The monitorial citizen is not an absentee citizen but watchful, even while he or she is doing something else" (Schudson 1998, 311). Twitter facilitates this type of monitorial citizenship: it can be used rather passively by seemingly inactive citizens, who can nevertheless be watchful of police behavior. Although Twitter does not result in immediate radically different interaction patterns, there might be potential for better long-term monitoring of police behavior. Future research endeavors should look into these potential long-term effects.

The answer to the second part of the question provides the second contribution of this article because we gained more understanding of how and why social media relate to legitimacy. Our research shows that Twitter use affects perceived legitimacy of the police through both the cognitive route-effectiveness is communicated through social media, and this stream of communications strengthens citizens' perceptions of police effectiveness - and the affective route-the police demonstrate that they are in touch with society and "modern," and this strengthens their legitimacy. Furthermore, we found that of the two sources of perceived legitimacy, procedural fairness and effectiveness, only perceived effectiveness was significant. Twitter messages more often communicate police successes (Campbell, Lambright, and Wells 2014) and do not contain many cues for citizens to assess whether the police treat citizens fairly or not. Procedural fairness may be shaped more strongly in direct interactions with the police or by placing other content on Twitter: the police may want not only to communicate their results and actions but also promote safeguarding procedural fairness.

This study has a few limitations that call for follow-up research. A first limitation is the focus on communication patterns omitting the content of the communication. In future research, it is important to analyze the relationship between the content of police social media communications and perceived effectiveness. A second substantial limitation is our exclusive focus on Twitter communications by government organizations. We only investigated the use of Twitter and its effect, and it remains unclear whether our findings can be generalized to other social media platforms, such as YouTube or Facebook. Both have some distinct characteristics that affect how citizens receive information and/or interact with the police. YouTube is mainly based on video material instead of text, which makes police cases more accessible to a broader public. Facebook is a closed network that may attract fewer followers, yet those who do follow the police on Facebook might be more supportive of them and interact more. Future research should thus investigate these potentially different effects on perceived legitimacy.

A methodological limitation is that the study design is crosssectional, that is, focused on one group at one moment in time. This type of research does not establish the direction of relations, and therefore making empirical causal inferences is not justified. Although we have theoretical reasons to presume the direction of the social media effect, it is conceivable that reverse causality may occur as well. For instance, citizens who perceive the police as highly legitimate may be more likely to follow the police on Twitter. 
Likewise, those who are less supportive might not want to follow police Twitter accounts because they may not find them a trustworthy source of information. Future experimental studies would be useful to establish the causality of these patterns.

\section{Conclusion}

The capacities of social media to enable transparency and its participative nature have been lauded by many scholars (e.g., Bertot, Jaeger, and Grimes 2010; Mergel 2012b; Yi, Oh, and Kim 2013, 310). Our article shows that this assumption should be more nuanced concerning Twitter, one of the major social media platforms. Twitter has a limited reach within the population, and it is hardly ever used to interact with the police, indicating that the debate about new technologies and citizen participation remains ongoing. The hopes about social media contributing to citizen participation are very similar to the initial hopes surrounding the Internet in the early 2000s (e.g., Thomas and Streib 2003; Tolbert and Mossberger 2006; Welch, Hinnant, and Moon 2005); the limited degree of citizen participation through Twitter is similar to first assessments of the contribution of the Internet to citizen participation.

Still, social media generally seem to offer the police an opportunity to "disintermediate" relations with citizens (Edwards 2006). The news media tends to focus on mistakes and failures (Schillemans 2012), whereas social media offers the opportunity to highlight successes. Open government increases the opportunity for public scrutiny but also, at the same time, strengthens its capacity to shape public relations. For some police departments, this is exactly the reason for wanting to use social media (Meijer and Thaens 2013; see also Campbell, Lambright, and Wells 2014). Possibly, journalists remain the main followers of Twitter accounts of local police departments and use information from Twitter to report on crimes and police behavior. Future research could also examine the relationship between journalistic descriptions, social media, and legitimacy. Because so few respondents use Twitter according to our study, this effect is perhaps more important than the effect caused by direct use.

Overall, we conclude that using Twitter to establish a direct channel of communication with citizens and to communicate successes helps the police—albeit slightly—strengthen perceived police legitimacy.

\section{Acknowledgments}

The LISS panel data were collected by CentERdata (Tilburg University) through its MESS project funded by the Netherlands Organization for Scientific Research. A previous version of this article was presented in PSG 1 at the European Group for Public Administration Conference in 2013. The authors specifically thank Victor Bekkers for his useful comments on the article.

\section{Notes}

1. This case description is partly based on Meijer et al. (2013).

2. We translated the original items from Dutch into English for this article.

\section{References}

Anderson, James C., and David D. Gerbing. 1988. Structural Equation Modeling in Practice: A Review and Recommended Two-Step Approach. Psychological Bulletin 103(3): 411-23.
Bekkers, Victor, and Vincent Homburg. 2007. The Myths of E-Government: Looking beyond the Assumptions of a New and Better Government. Information Society 23(5): 373-82.

Bentler, Peter M. 1990. Comparative Fit Indexes in Structural Models. Psychological Bulletin 107(2): 238-46.

Bertot, John C., Paul T. Jaeger, and Justin M. Grimes. 2010. Using ICTs to Create a Culture of Transparency: E-Government and Social Media as Openness and Anti-Corruption Tools for Societies. Government Information Quarterly 27(3): 264-71.

Bertot, John C., Paul T. Jaeger, and Derek Hansen. 2012. The Impact of Polices on Government Social Media Usage: Issues, Challenges, and Recommendations. Government Information Quarterly 29(1): 30-40.

Bingham, Lisa Blomgren, Tina Nabatchi, and Rosemary O'Leary. 2005. The New Governance: Practices and Process for Stakeholder and Citizen Participation in the Work of Government. Public Administration Review 65(5): 547-58.

Bonsón, Enrique, Lourdes Torres, Sonia Royo, and Francisco Flores. 2012. Local E-Government 2.0: Social Media and Corporate Transparency in Municipalities. Government Information Quarterly 29(2): 123-32.

Boyd, Danah M., and Nicole B. Ellison. 2007. Social Network Sites: Definition, History, and Scholarship. Journal of Computer-Mediated Communication 13(1): 210-30.

Campbell, David A., Kristina T. Lambright, and Christopher J. Wells. 2014. Looking for Friends, Fans, and Followers? Social Media Use in Public and Nonprofit Human Services. Public Administration Review 74(5): 655-63.

Criado, J. Ignacio, Rodrigo Sandoval-Almazan, and J. Ramon Gil-Garcia. 2013. Government Innovation through Social Media. Government Information Quarterly 30(4): 319-26.

Crump, Jeremy. 2011. What Are the Police Doing on Twitter? Social Media, the Police, and the Public. Policy and Internet 3(4): 1-27.

de Fine Licht, Jenny. 2011. Do We Really Want to Know? The Potentially Negative Effect of Transparency in Decision-Making on Perceived Legitimacy. Scandinavian Political Studies 34(3): 183-201.

de Fine Licht, Jenny, Daniel Naurin, Peter Esaiasson, and Mikael Gilljam. 2013. When Does Transparency Generate Legitimacy? Experimenting on a ContextBound Relationship. Governance 27(1): 111-34.

Edwards, Arthur R. 2006. ICT Strategies of Democratic Intermediaries: A View on the Political System in the Digital Age. Information Polity 11(2): $163-76$.

Elsbach, Kimberly D. 1994. Managing Organizational Legitimacy in the California Cattle Industry: The Construction and Effectiveness of Verbal Accounts. Administrative Science Quarterly 39(1): 57-88.

Fishman, Mark, and Gray Cavender, eds. 1998. Entertaining Crime: Television Reality Programs. New York: Aldine de Gruyter.

Fledderus, Joost, Taco Brandsen, and Marlies Honingh. 2014. Restoring Trust through the Co-Production of Public Services: A Theoretical Elaboration. Public Management Review 16(3): 424-43.

Grimmelikhuijsen, Stephan G., and Albert J. Meijer. 2014. The Effects of Transparency on the Perceived Trustworthiness of a Government Organization: Evidence from an Online Experiment. Journal of Public Administration Research and Theory 24(1): 137-57.

Grimmelikhuijsen, Stephan G., Gregory Porumbescu, Boram Hong, and Tobin Im. 2013. The Effect of Transparency on Trust in Government: A Cross-National Comparative Experiment. Public Administration Review 73(4): 575-86.

Hawdon, James E., John Ryan, and Sean P. Griffin. 2003. Policing Tactics and Perceptions of Police Legitimacy. Police Quarterly 6(4): 469-91.

Heverin, Thomas, and Lisl Zach. 2011. Law Enforcement Agency Adoption and Use of Twitter as a Crisis Communication Tool. In Crisis Information Management: Communication and Technologies, edited by Christine Hagar, 25-42. Oxford, UK: Woodhead. 
Hinds, Lyn, and Kristina Murphy. 2007. Public Satisfaction with Police: Using Procedural Justice to Improve Police Legitimacy. Australian and New Zealand Journal of Criminology 40(1): 27-42.

Keane, John. 2009. The Life and Death of Democracy. New York: W. W. Norton.

Kim, Suk Kyoung, Min Jae Park, and Jae Jung Rho. 2015. Effect of the

Government's Use of Social Media on the Reliability of the Government: Focus on Twitter. Public Management Review 17(3): 328-55.

Lewis, J. David, and Andrew Weigert. 1985. Trust as a Social Reality. Social Forces 63(4): 967-85.

Lipset, Seymour M. 1959. Some Social Requisites of Democracy: Economic Development and Political Legitimacy. American Political Science Review 53(1): 69-105.

McAllister, Daniel J. 1995. Affect- and Cognition-Based Trust as Foundations for Interpersonal Cooperation in Organizations. Academy of Management Journal 38(1): 24-59.

McDermott, Patrick. 2010. Building Open Government. Government Information Quarterly 27(4): 401-13.

Meijer, Albert J., Deirdre Curtin, and Maarten Z. Hillebrandt. 2012. Open Government: Connecting Vision and Voice. International Review of Administrative Sciences 78(1): 10-29.

Meijer, Albert J., Stephan G. Grimmelikhuijsen, Danielle Fictorie, Marcel Thaens, and Peter Siep. 2013. Politie en sociale media: Van Hype naar onderbouwde keuzen [Police and Social Media: From Hype to Informed Choices]. Amsterdam: Reed Business.

Meijer, Albert J., and Marcel Thaens. 2013. Social Media Strategies: Understanding the Differences between North American Police Departments. Government Information Quarterly 30(4): 343-50.

Mergel, Ines. 2012a. The Social Media Innovation Challenge in the Public Sector. Information Polity 17(3-4): 281-92.

-2012b. Social Media in the Public Sector: Participation, Collaboration, and Transparency in the Networked World. San Francisco: Jossey-Bass.

- 2013. A Framework for Interpreting Social Media Interactions in the Public Sector. Government Information Quarterly 30(4): 327-34.

Mergel, Ines, and Stuart I. Bretschneider. 2013. A Three-Stage Adoption Process for Social Media Use in Government. Public Administration Review 73(3): 390-400.

Morgeson, Forest V., III, David VanAmburg, and Sunil Mithas. 2011. Misplaced Trust? Exploring the Structure of the E-Government-Citizen Trust Relationship. Journal of Public Administration Research and Theory 21(2): 257-83.

Mossberger, Karen, Yonghong Wu, and Jared Crawford. 2013. Connecting Citizens and Local Governments? Social Media and Interactivity in Major U.S. Cities. Government Information Quarterly 30(4): 351-58.

Nationale Politie [National Police]. 2012. Realisatieplan Nationale Politie. http:// www.rijksoverheid.nl/documenten-en-publicaties/kamerstukken/2012/12/07/ realisatieplan-nationale-politie.html [accessed March 23, 2015].

Oliveira, Gustavo Henrique Maultasch, and Eric W. Welch. 2013. Social Media Use in Local Government: Linkage of Technology, Task, and Organizational Context. Government Information Quarterly 30(4): 397-405.

Perin, Michelle. 2009. Twitter Me This, Twitter Me That. Law Enforcement Technology 36(9): 80-84.

R Development Core Team. 2008. The R Project for Statistical Computing. http:// www.R-project.org [accessed March 19, 2015].

Scharpf, Fritz W. 1999. Governing in Europe: Effective and Democratic? Oxford, UK: Oxford University Press.

Schillemans, Thomas. 2012. Mediatization of Public Services: How Public Organizations Adapt to News Media. Frankfurt, Germany: Peter Lang.

Schudson, Michael. 1998. The Good Citizen: A History of American Public Life. New York: Free Press.

Suchman, Mark C. 1995. Legitimacy: Strategic and Institutional Approaches. Academy of Management Review 20(3): 571-610.
Suddaby, Roy, and Royston Greenwood. 2005. Rhetorical Strategies of Legitimacy. Administrative Science Quarterly 50(1): 35-67.

Sunshine, Jason, and Tom R. Tyler. 2003. The Role of Procedural Justice and Legitimacy in Shaping Public Support for Policing. Law and Society Review 37(3): 513-48.

Thomas, John Clayton, and Gregory Streib. 2003. The New Face of Government: Citizen-Initiated Contacts in the Era of E-Government. Journal of Public Administration Research and Theory 13(1): 83-102.

Tolbert, Caroline J., and Karen Mossberger. 2006. The Effects of E-Government on Trust and Confidence in Government. Public Administration Review 66(3): 354-69.

Tyler, Tom R. 1997. The Psychology of Legitimacy: A Relational Perspective on Voluntary Deference to Authorities. Personality and Social Psychology Review 1(4): 323-45.

- 2003. Procedural Justice, Legitimacy, and the Effective Rule of Law. Crime and Justice 30: 283-357.

2004. Enhancing Police Legitimacy. Annals of the American Academy of Political and Social Science 593: 84-99.

- 2006. Psychological Perspectives on Legitimacy and Legitimation. Annual Review of Psychology 57: 375-400.

Tyler, Tom R., and Peter Degoey. 1995. Collective Restraint in Social Dilemmas: Procedural Justice and Social Identification Effects on Support for Authorities. Journal of Personality and Social Psychology 69(3): 482-97.

Van den Bos, Kees, Riël Vermunt, and Henk A. M. Wilke. 1997. Procedural and Distributive Justice: What Is Fair Depends More on What Comes First than on What Comes Next. Journal of Personality and Social Psychology 72(1): 95-104.

Weber, Max. 1968. Economy and Society. Edited by Günther Roth and Claus Wittich. New York: Bedminster.

Welch, Eric W., Charles C. Hinnant, and M. Jae Moon. 2005. Linking Citizen Satisfaction with E-Government and Trust in Government. Journal of Public Administration Research and Theory 15(3): 371-91.

Yi, Myongho, Sam Gyun Oh, and Sunghun Kim. 2013. Comparison of Social Media Use for the U.S. and the Korean Governments. Government Information Quarterly 30(3): 310-17.

Yuan, Ke-Hai, and Peter M. Bentler. 2004. On Chi-Square Difference and z Tests in Mean and Covariance Structure Analysis When the Base Model Is Misspecified. Educational and Psychological Measurement 64(5): 737-57.

\section{Appendix \\ Use of Social Media}

- Informative use of social media/transparency: "Are you currently following a Twitter account of the police?” (yes/no)

- Interactive use of social media/participation: "Have you ever responded to a police request for information about a suspect or missing person?" (no/yes)

\section{Perceived Effectiveness}

Translated and adapted from scales used by Tyler (1997) and Hinds and Murphy (2007) (alpha $=.823$, range 1-5)

- EFFECT1: "The police successfully fight crime."

- EFFECT2: "The police do whatever they can to trace suspects, missing persons, and goods."

- EFFECT3: "When it really matters, the police will do the utmost to help you."

\section{Perceived Procedural Fairness}

Translated and adapted from scales used by Tyler (1997) and Hinds and Murphy (2007) (alpha $=.848$, range 1-5) 
- PROCESS1: "In the execution of their tasks, the police respect citizens' rights."

- PROCESS2: "You can rely on just actions and behavior from the police."

- PROCESS3: "The police treat every citizen equally."

\section{Legitimacy}

Translated and adapted from scales used by Tyler (1997) and Hinds and Murphy (2007) (alpha $=.829$, range $1-5)$

- LEGIT1: "I have much respect for the work of the police."

- LEGIT2: "I trust the police."

- LEGIT3: "I always follow police officers' orders, even if I think otherwise."

- LEGIT4: "Please indicate how satisfied you are with the general performance of the police on a scale from 1 to 10 ."

\section{Control Variables}

We used the following as control variables:

- "What is your sex?" ( 1 = male, 2 = female $)$

- "What is your age?"

- "What is the highest level of education that you attained?" (recoded as a dummy variable, $0=$ low, 1 = high)

- Perceived safety (two items, alpha = .884)

o "I sometimes feel unsafe in my neighbourhood."

o "I sometimes feel unsafe in my city." ( 1 = totally agree, 5 = totally disagree)

- "Have you been a victim of a crime in the past twelve months (regardless the degree of the crime)?" ( $0=$ no, $1=$ yes $)$ 